\title{
"LAUREADO ESCULTOR, PERFECTO CABALLERO Y PADRE AMANTÍSIMO..." Y POBRE: EN EL CENTENARIO DE LA MUERTE DEL ESCULTOR JOSÉ GONZÁLEZ Y GIMÉNEZ
}

\author{
"HONOURED SCULPTOR, PERFECT GENTLEMAN AND \\ LOVING FATHER..." AND POOR: ON THE FIRST \\ CENTENARY OF THE DEATH OF THE SCULPTOR \\ JOSÉ GONZÁLEZ Y GIMÉNEZ
}

\author{
Ángel Justo Estebaranz \\ Universidad de Sevilla. España \\ ajestebaranz@us.es
}

José González y Giménez, escultor granadino que desempeñó una importante labor docente en diferentes instituciones académicas en Ecuador y en España, pasó sus últimos años en Córdoba. Siendo poco conocida su producción y su periplo vital, había un desconocimiento total de las circunstancias de sus últimos momentos. Gracias a las fuentes hemerográficas y a documentación inédita procedente del archivo de la Real Academia de Bellas Artes de San Fernando, hemos podido reconstruir sus postreros momentos como docente y también los amargos años que pasó hasta su deceso. En este trabajo abordamos la situación de González y Giménez en su etapa final, así como el papel que desempeñaron otros artistas en su jubilación.

Palabras clave: José González y Giménez; Córdoba; Escuela Superior de Artes e Industrias; Mateo Inurria; Enrique Romero de Torres.

José González y Giménez, a sculptor born in Granada who played an important teaching role in different academies in Ecuador and Spain, spent his last years in Cordoba. Being little known its production and his life, there was a total ignorance of the circumstances of his last years. Thanks to the hemerographic sources and to unpublished documents from the archive of the Real Academia de Bellas Artes de San Fernando, we have been able to reconstruct his last moments as a teacher and also the bitter years that passed until his death. In this paper we address the situation of González y Giménez in his last years of life, as well as the role played by other artists in his retirement.

Keywords: José González y Giménez; Cordoba; Escuela Superior de Artes e Industrias; Mateo Inurria; Enrique Romero de Torres. 


\section{INTRODUCCIÓN}

El 16 de enero de 1917 fallecía en Córdoba el escultor granadino José González y Giménez ${ }^{1}$. Este artista fue un destacado profesor en las distintas instituciones académicas en que desempeñó su labor docente, llegando incluso a dirigir alguna de ellas, como la de Quito y la de Córdoba, aunque esta con carácter accidental. A pesar de los premios que obtuvo, sobre todo en su periodo de formación y primeros años de carrera, el conocimiento sobre su figura es muy escaso. Son muy pocos los trabajos monográficos que se le han dedicado, interesándose los investigadores por esculturas concretas trabajadas por el $\operatorname{artista}^{2}$. Nosotros nos acercamos al autor a raíz de su presencia en Quito como director de la Academia de Bellas Artes ${ }^{3}$. Esta falta de atención a su figura está también relacionada con el hecho de que no se han localizado varias de las obras realizadas por él, sumando la circunstancia de que algunas de ellas eran monumentos que quedaron en el boceto y nunca se llegaron a materializar en piedra o en bronce. Pero González y Giménez tuvo, tras su periodo de formación en Madrid y en Roma, una importancia notable en la introducción de los estudios académicos de Bellas Artes en Ecuador, y luego recorrió diversas ciudades españolas como profesor. Además, el reconocimiento académico español le llegaría en 1888, cuando fue nombrado académico correspondiente de la Real de Bellas Artes de San Fernando. Precisamente por su nombramiento como correspondiente de esta institución nos interesamos por la relación que pudo tener con ella, y logramos localizar un interesante expediente sobre su fallecimiento, cuya fecha no se conocía hasta el momento, cuando se cumple un siglo del mismo. A partir de este expediente también encontramos otras noticias relativas a la muerte del artista y de su esposa, aparecidas en los periódicos cordobeses. En este artículo analizamos estos

${ }^{1}$ Aunque en los periódicos se hace referencia a él como "González Jiménez”, el artista siempre firmó como "González y Giménez", motivo por el cual mantenemos esta grafía.

2 PARDO CANALÍS, Enrique: "Informe de Federico de Madrazo sobre colocación en el Real Museo de una escultura, en yeso, de González Jiménez", Boletín de la Sociedad Española de Excursiones, 52, 1948, pp. 229-232; FERNÁNDEZ FERNÁNDEZ, Xosé: "El escultor José González Giménez y su fracasado proyecto de estatua a María Pita", Abrente, 21-22, 1989-1990, pp. 88-99; y KENNEDY TROYA, Alexandra: "Sucre, un secreto, una estatua", en FREIRE RUBIO, E.: Quito: tradiciones, testimonio y nostalgia. T. IV. Quito, 2002, pp. 240-243. A estos trabajos antecedió en el tiempo la entrada que le dedicó Francisco Cuenca en su Museo de pintores y escultores andaluces contemporáneos, aparecido solo seis años después de la muerte del escultor. Véase CUENCA, Francisco: Museo de pintores y escultores andaluces contemporáneos. Habana, 1923, pp. 178-179.

3 JUSTO ESTEBARANZ, Ángel: "José González y Giménez y el Monumento a Sucre en Quito", Sémata, 24, 2012, pp. 395-413; y JUSTO ESTEBARANZ, Ángel: "El escultor español José González y Giménez y la Academia Nacional de Bellas Artes de Quito", en Mirando a Clío: el arte español espejo de su historia. Santiago de Compostela, 2012, pp. 1318-1326. 
documentos y noticias periodísticas, poniendo de relieve datos desconocidos sobre su familia y su situación económica en sus últimos años, motivada por una decisión administrativa que lo dejó en precario. Asimismo, nos interesamos por las relaciones que estableció con otros artistas en su etapa docente en Córdoba.

\section{UNA ÉPOCA DIFÍCIL: LOS ÚLTIMOS AÑOS Y LA MUERTE DEL ARTISTA}

El deceso de José González y Giménez se produjo el martes 16 de enero de 1917. La muerte le llegaba en Córdoba, ciudad donde se había asentado por motivos laborales, y no en Sevilla, donde la situaba Cuenca ${ }^{4}$. Como indica Pardo Canalís, el traslado se produjo por permuta en 1908, procedente de Sevilla ${ }^{5}$. Aunque de muy avanzada edad -ya había cumplido los 70 años-, se pudo dedicar a la docencia en esta ciudad otros tres años. De hecho, a comienzos del mes de noviembre de 1911 se informaba favorablemente sobre la continuación del escultor en el servicio activo ${ }^{6}$. Incluso llegó a ser director interino de la Escuela de Artes e Industrias ${ }^{7}$. Pero la década que pasó en Córdoba estaría plagada de sucesos tristes en el ámbito personal y académico de González y Giménez.

La noticia del fallecimiento del escultor aparecía en la prensa cordobesa un día después del deceso, en la edición del miércoles 17. El breve texto que publicaba el diario El defensor de Córdoba indicaba lo siguiente: "Ha entregado su alma á Dios D. José González Jiménez, catedrático numerario de la Escuela de Artes é Industrias de esta capital. Descanse en paz el alma del finado". La necrología sería publicada ese mismo día en el Diario de Córdoba ${ }^{9}$. Firmada por "Omaya" y escrita a una columna, recogía los principales hitos de la vida del artista andaluz. Se indicaba en este breve escrito que el fallecimiento se había producido el día anterior. El artista, nombrado como catedrático numerario, se encontraba ya jubilado. Considerado como "laureado escultor, perfecto caballero y padre amantísimo", su muerte fue muy sentida en el mundo del arte.

${ }^{4}$ Este autor señalaba que González y Giménez falleció en Sevilla siendo profesor de escultura en la Escuela de Bellas Artes. Véase CUENCA, Francisco: Museo de pintores y escultores..., op. cit., p. 179.

5 PARDO CANALÍS, Enrique: "Informe de Federico de Madrazo...", op. cit., p. 231.

${ }^{6}$ La Mañana, año III, no 695, 4-11-1911, p. 5; Gaceta de Instrucción Pública y Bellas Artes, año XXIII, n 1.115, 5-11-1911, p. 476; y Gaceta de Instrucción Pública y Bellas Artes, año XXIII, no 1.116, 10-11-1911, p. 484.

7 Como "Director A." -accidental- aparece dando el visto bueno al aviso de matrícula para el curso 1910-1911 en ese centro. Este aviso está publicado en el Diario de Córdoba, año LXI, n $18.438,18-8-1910$, p. 1.

${ }^{8}$ El defensor de Córdoba, año XIX, no 5.301, 17-1-1917, p. 2.

9 Diario de Córdoba, año LXVIII, nº 20.619, 17-1-1917, p. 2. 
El texto hacía hincapié en los reconocimientos que tuvo por parte de la realeza y de las corporaciones y academias, pero también en la situación de desamparo en que había pasado sus últimos días. Según el diario cordobés, González y Giménez había muerto pobre y olvidado, pero legando a sus hijos "un nombre honrado y una memoria gloriosa", así como una pluralidad de reconocimientos y premios que quedan detallados en el texto. Así, se resaltan los honores que le dispensaron la reina Isabel II, el infante don Gabriel de Borbón "y otras distinguidas personalidades, academias y corporaciones". Coincidiendo con su estancia en Roma, donde estudió escultura, anatomía pictórica, geometría, perspectiva y óptica, recibió un premio en la Exposición Nacional de 1862 por su estatua Ganimedes, y otro en la Exposición Nacional de 1867 por el grupo en yeso Los últimos momentos de Numancia. Años después, sería premiado con medalla de plata por el Liceo Brigantino de La Coruña. Asimismo, durante su estadía en Roma, ganaría en 1867 otra medalla de oro a cargo de la Academia Pontificia de Santa Cecilia por su busto de Rossini. Pero no sería ese el único reconocimiento que recibió en la ciudad italiana, pues también fue nombrado profesor de mérito por la Insigne Pontificia Academia de Bellas Artes de Virtuosos del Panteón.

Sin embargo, todo ello no sirvió para impedir que viviese su ancianidad "amargada por la garra cruel de la pobreza", y que sus hijos quedasen "sumidos en el más espantoso desamparo", teniendo como esperanza la caridad de las autoridades cordobesas. Por ello, el texto terminaba interpelando a esas mismas autoridades, concretamente a los excelentísimos señores gobernador, alcalde, autoridades, corporaciones y entidades, para que les entregasen una bendita limosna, ya que no podían costearle el sepelio. Para ello facilitaba las señas de los descendientes, que vivían en la calle de los Moriscos, número 17.

Sabemos que al momento de fallecer, José González y Giménez ya se encontraba viudo. En efecto, su esposa, doña Carolina Ricci Zelony, había fallecido el 13 de agosto de 1909. De su muerte tras larga enfermedad se hicieron eco varios periódicos locales, que se referían a ella como una "virtuosa señora" ${ }^{10}$. Se indicaba que su esposo era en ese momento director interino de la Escuela de Artes Industriales. Asimismo, que la finada era madre política del escritor don José del Real Rodríguez ${ }^{11}$. Pocos meses antes del deceso, el escritor y periodista sevillano

${ }^{10}$ Diario de Córdoba, año LX, n $18.072,14-8-1909$, p. 2; y El defensor de Córdoba, año XI, n $2.993,13-8-1909$, p. 3. La única diferencia en ambas publicaciones se encuentra en el pésame transmitido al final a la familia. El resto del texto es igual.

${ }^{11}$ Este escritor fue director de la revista De Agricultura. Revista quincenal de propaganda y defensa de los intereses agrícolas de la Región. Véase PARIAS SÁINZ DE ROZAS, María: "Prensa y agricultura en la Sevilla contemporánea. Los fondos de la Hemeroteca Municipal”, en Comunicación, historia y sociedad: homenaje a Alfonso Braojos. Sevilla, 2001, p. 203. Según Urrutia, José del Real Rodríguez firmó algunos poemas a finales del siglo XIX. Véase URRUTIA, Jorge: "La prehistoria poética de Juan Ramón Jiménez: 
había contraído matrimonio con la hija del artista, Aurelia González Ricci. El novio había llegado a Córdoba a comienzos de $1909^{12}$. En los primeros días de marzo se firmaban los esponsales en la parroquia de San Lorenzo ${ }^{13}$. A fines de ese mes se anunciaba en la prensa cordobesa la proximidad del enlace, que tendría lugar a comienzos del mes siguiente ${ }^{14}$. El matrimonio se celebró en la tarde del miércoles 7 de abril en la iglesia parroquial de San Lorenzo ${ }^{15}$. Se indicaba en la nota de prensa que los recién casados marcharían a Sevilla una temporada, para volver después a Córdoba. Asimismo, que habían sido testigos, por parte de la novia, Arcadio Rodríguez y Eduardo Vassallo, este último catedrático de la Escuela Superior de Artes e Industrias, compañero de su padre ${ }^{16}$. Sabemos que la pareja marchó a Sevilla

confusiones y diferencias", en Juan Ramón Jiménez: poesía total y obra en marcha: actas del IV Congreso de Literatura Española Contemporánea. Barcelona, 1991, p. 51. Fundó en 1914 el magazine Huelva en Fiestas. Véase PEÑA GUERRERO, María Antonia: El sistema caciquil en la provincia de Huelva. Clase política y partidos (1898-1923). Córdoba, 1993, p. 178. Era administrador de Arco Iris. Revista quincenal Literaria, de Artes, Ciencias, Modas y Salones. Véase, por ejemplo, Arco Iris. Revista quincenal Literaria, de Artes, Ciencias, Modas y Salones, año I, n ${ }^{\circ}$ 10, 30-10-1906. En la p. 77, escribe un poema, "A una rubia".

${ }_{12}$ Diario de Córdoba, año LX, nº 17.874, 26-1-1909, p. 2.

13 Aquí la hija aparece nombrada como Amelia González Ricci. Véase El defensor de Córdoba, año XI, n 2.862, 5-3-1909, p. 2.

${ }_{14}$ Diario de Córdoba, año LX, nº 17.934, 28-3-1909, p. 2.

15 Diario de Córdoba, año LX, nº 17.945, 8-4-1909, p. 2; y El defensor de Córdoba, año XI, no 2.889, 10-4-1909, p. 2.

${ }^{16}$ Eduardo Vassallo Dorronsoro (1868-1932) era pintor. Como su hijo, el escultor Juan Luis Vassallo, ejerció la docencia en las llamadas Escuelas de Artes y Oficios, "con una fuerte vocación a lo largo de toda su vida, llegando ambos a ser Directores del centro". Véase VASSALLO MAGRO, Marta: Juan Luis Vassallo. Vida y obra escultórica. T. 1. Tesis Doctoral. Madrid, 2014, p. 30. Disponible en http://eprints.ucm.es/29650/1/T35972.pdf (Consultado el 8-10-2017). A Córdoba llegaría como profesor tras ser nombrado, por Real Orden de 10 de julio de 1907, profesor numerario de aritmética, álgebra, geometría y trigonometría de la Escuela de Artes Industriales de la ciudad. Véase Diario de Córdoba, año LVIII, $\mathrm{n}^{\circ} 17.324,16-7-1907$, p. 2, donde se presenta su hoja de méritos y servicios. Al mes siguiente de asistir al enlace matrimonial de la hija de González y Giménez, se le concedía una gratificación por acumulación de Cátedra. Aparecía nombrado entonces como profesor de la Escuela de Artes Industriales de Córdoba. Véase Gaceta de instrucción pública y bellas artes, año XXI, nº 939, 10-5-1909, p. 1559. En agosto de 1911 firmaba como director accidental de la Escuela la convocatoria de matrícula para el curso 1911-1912. Véase Diario de Córdoba, año LXII, no 18.800, 19-8-1911, p. 1. En noviembre de 1911 se encargó de la clase de dibujo lineal de la Escuela de Artes y Oficios de Córdoba. Véase El defensor de Córdoba: diario católico, año XVI, n 4.626, 11-11-1914, p. 2. Vassallo sería nombrado director de la Escuela de Artes y Oficios de Córdoba en diciembre de 1911. Véase La Correspondencia de España, año LXII, no 19.667, 17-12-1911, p. 5. Por lo tanto, fue él quien sucedió a Inurria en la dirección de la Escuela. Tras su periplo cordobés, se trasladaría a 
a comienzos de diciembre de 1909 , como indicaba la prensa local ${ }^{17}$. Al momento del enlace, José del Real Rodríguez era secretario de la Unión Liberal Obrera de Córdoba. A Sevilla volvería en 1910 a pasar las fiestas de Semana Santa ${ }^{18}$. Probablemente la primavera de 1909 fuera uno de los momentos más felices de la familia en Córdoba, con el padre como director de la Escuela, el joven matrimonio recién casado y la madre aún viva. Pero poco después se empezarían a acumular las desgracias. Según recogía el diario El defensor de Córdoba con motivo del tercer aniversario de Carolina Ricci, la señora había fallecido víctima de una rápida dolencia, pero esta información se contradice con la supuesta larga enfermedad de que se daba noticia al momento de su fallecimiento ${ }^{19}$. En la nota de prensa se indicaba que esta señora se había distinguido por sus buenas obras para con los necesitados, lo que hizo que su muerte fuera muy sentida.

Pero el matrimonio de Aurelia González y José del Real no tuvo ocasión de prolongarse más que siete años, pues el marido falleció en Sevilla en $1916^{20}$. Este dato ayuda a entender la penosa situación en que vivían los descendientes de González y Giménez, pues jubilado el padre y fallecido el marido, Aurelia debió de encontrarse sola y desamparada cuando el largo desempeño docente de su padre debería haber dejado cubiertas las necesidades de la familia. Sin embargo, y habiendo una situación en la que su madre pudo ejercer la caridad, ahora los hijos tenían que acudir a la misma caridad.

Baeza en 1922, ejerciendo la docencia en la Escuela de Bellas Artes de Baeza, población en la que falleció en 1932. Véase Diccionario de pintores y escultores españoles del siglo XX. Vol. 14. Madrid, 1994, p. 4386; y VASSALLO MAGRO, Marta: Juan Luis Vassallo..., op. cit., p. 37. Por su parte, Arcadio Rodríguez era médico, y formó parte de La Esperanza, sociedad benéfica que comenzaría a funcionar desde el 1 de enero de 1911. Véase El defensor de Córdoba, año XII, n 3.382, 10-11-1910, p. 2.

${ }^{17}$ El defensor de Córdoba, año XI, no 3.090, 3-12-1909, p. 3.

18 El defensor de Córdoba, año XII, no 3.178, 10-4-1910, p. 2. Allí volvería en diciembre de ese año, con su mujer. Véase El defensor de Córdoba, año XII, n 3.400, 2-12-1910, p. 2. En marzo de 1911 aparece de nuevo en Córdoba. Aquí es nombrado como secretario de la revista ilustrada Arco Iris. Véase El defensor de Córdoba, año XIII, nº 3.489, 17-3-1911, p. 2. A partir de ese año se encargaría de publicar el álbum con el programa oficial de la feria de Nuestra Señora de la Salud. En el programa de 1911 se veían "varias preciosas vistas de Córdoba" alabadas por la prensa local. Véase El defensor de Córdoba, año XIII, n ${ }^{\circ}$ 3.540, 16-5-1911, p. 2. El año siguiente se encargaba de los trabajos directivos del Álbum de la Feria de la Salud, que incluía también fotografías. Véase El defensor de Córdoba, año $\mathrm{XIV}, \mathrm{n}^{\circ} 3.857,18-5-1912$, p. 2. En el de 1913 incluía una portada pintada por el artista sevillano Moyano. Véase El defensor de Córdoba, año XV, n 4.127, 4-4-1913, p. 2.

${ }^{19}$ El defensor de Córdoba, año XIV, nº 3.927, 12-8-1912, p. 2.

${ }^{20}$ Diario de Córdoba, año LXVII, nº 20.401, 16-6-1916, p. 2. 


\section{LAS PESQUISAS REALIZADAS DESDE LA ACADEMIA DE SAN FERNANDO}

Una muestra de cómo el olvido pudo caer sobre este artista de larga trayectoria la constituyen las pesquisas que desde la Real Academia de Bellas Artes de San Fernando se hicieron en torno a su figura en los meses previos a su fallecimiento. Con esta institución tenía González y Giménez relación desde hacía décadas, llegando incluso a ser nombrado académico correspondiente por La Coruña el 12 de marzo de $1888^{21}$. En ese momento hacía pocos meses que se encontraba trabajando como profesor numerario de la Escuela Provincial de Bellas Artes de La Coruña, donde había llegado para ocupar dicho cargo por Real Orden de 24 de octubre de $1887^{22}$.

El primer documento que integra el expediente de la Academia de San Fernando es una carta en la que Enrique Romero de Torres, director del Museo de Bellas Artes de Córdoba y académico de San Fernando, contestaba a una petición de don Antonio Garrido Villazán solicitando información sobre González y Giménez ${ }^{23}$. En esta misiva, fechada el 20 de agosto de 1916, lamentaba desconocer la profesión del académico correspondiente, cuya residencia se había trasladado desde Sevilla a Córdoba, y a quien no conocía todavía. Y ello a pesar de las investigaciones que habían hecho varios compañeros de la Academia. Esta afirmación adelanta las pesquisas a algún tiempo antes, cuando Garrido solicitó los datos. Las pesquisas infructuosas hasta ese momento resultan cuanto menos extrañas, pues hasta hacía cinco años González y Giménez había sido profesor en la escuela cordobesa. Por lógica debería de ser conocido entre los artistas cordobeses, más aún cuando en 1909, uno de los testigos del matrimonio de su hija había sido Eduardo Vassallo, también profesor en el centro. Quizás Romero de Torres no preguntó a quien entre los docentes tenía una relación más cercana con el escultor.

${ }^{21}$ GARCÍA SEPÚLVEDA, María Pilar y NAVARRETE MARTÍNEZ, Esperanza: Relación general de académicos (1752-2015). Madrid, 2016, p. 212. Disponible en http:// www.realacademiabellasartessanfernando.com/assets/docs/academicos/relacion_general_de_academicos.pdf (Consultado el 26-10-2017). El escultor granadino figuraría en el Anuario de la Academia a partir del año siguiente. Véase Real Academia de Bellas Artes de San Fernando. Año de 1889. Madrid, 1889, p. 76.

${ }^{22}$ PARDO CANALÍS, Enrique: "Informe de Federico de Madrazo...”, op. cit., p. 231.

${ }^{23}$ ARABASF (Archivo de la Real Academia de Bellas Artes de San Fernando), Comisión provincial de Monumentos históricos y artísticos de Córdoba, exp. 4-58-12, Carta de Enrique Romero de Torres a Antonio Garrido, 20-8-1916. Antonio Garrido y Villazán había ingresado en la Academia el 29 de marzo de 1903. Véase Discursos leídos ante la Real Academia de Bellas Artes de San Fernando en la recepción pública del señor D. Antonio Garrido y Villazán el día 29 de Marzo de 1903. Madrid, 1903. 
En respuesta a la carta anterior, contestaba Garrido en Madrid el 8 de septiembre de ese año. En la misiva indicaba que González y Giménez era desconocido. Pero le conminaba a encontrar a nuestro artista, "que debe ser persona conocida en el arte", y a comunicarle los datos que le tenía pedidos, y que consideraba muy necesarios ${ }^{24}$.

El 29 de septiembre, Enrique Romero de Torres mandaba una tarjeta postal, en la que indicaba a Garrido la continuación de sus pesquisas para conocer a González y Giménez. No obstante, estas aún no habían dado resultado, pues nadie le podía dar razón ${ }^{25}$. No obstante, señalaba que continuaría con sus investigaciones "policiacas" - sic, y subrayado, lo que da a entender que las pesquisas le estaban tomando un tiempo mayor del esperado-.

En carta firmada el 26 de enero de 1917 y dirigida a Antonio Garrido, Romero de Torres indicaba que tras volver de Sevilla, donde había pasado unos días, se encontró con la noticia del fallecimiento de González y Giménez ${ }^{26}$. Sabemos por los periódicos que el director del Museo cordobés había estado en la capital andaluza probablemente entre el 21 y el 25 de enero ${ }^{27}$. En la misiva enviada a Garrido, el pintor adjuntaba la necrología aparecida en el Diario de Córdoba, de la que tratamos en el apartado anterior. Y aportaba un dato fundamental para entender la situación de desconocimiento sobre su figura: desde que se retiró, González y Giménez hacía una vida tan retraída que casi nadie lo conocía en Córdoba. Por eso no se enteró de que vivía en Córdoba hasta que la noticia de la muerte apareció en el periódico. Y además, señalaba que tenía dos hijos: un varón y una hija. Al hijo sí lo conocía Romero de Torres, y fue él quien suministró la información biográfica al diario cordobés, con datos que ponderaba como "muy detallados". Señalaba Romero de Torres que a González y Giménez - "este pobre”, según sus palabras- lo obligó a jubilarse Mateo Inurria cuando era director de la Escuela de Artes y Oficios, y González y Giménez profesor de la misma. Le faltaba un año o año y medio para tener derechos pasivos, pero Inurria no tuvo consideración alguna. En vez de esperar el poco tiempo que faltaba, hizo que lo

${ }^{24}$ ARABASF, exp. 4-58-12, Carta de Antonio Garrido a Enrique Romero de Torres, 8-9-1916.

25 ARABASF, Comisión provincial de Monumentos históricos y artísticos de Córdoba, exp. 4-58-12, Tarjeta postal de Enrique Romero de Torres a Antonio Garrido, 29-91916. Al final del texto se ha escrito, con otra letra: "Gracias en 10 Enero 1917".

${ }^{26}$ ARABASF, Comisión provincial de Monumentos históricos y artísticos de Córdoba, exp. 4-58-12, Carta de Enrique Romero de Torres a Antonio Garrido, 26-1-1917.

${ }^{27}$ En la edición del día 22 del Diario de Córdoba se indicaba que el artista había marchado a Sevilla. Véase Diario de Córdoba, año LXVIII, n 20.624, 22-1-1917, p. 2. Por su parte, en la edición del 25 de enero de El defensor de Córdoba y del 26 de enero del Diario de Córdoba se anunciaba el regreso del pintor procedente de Sevilla. Véase El defensor de Córdoba, año XIX, nº 5.308, 25-1-1917, p. 2; y Diario de Córdoba, año LXVIII, nº 20.628, 26-1-1917, p. 1. 
jubilaran, dejándolo en la mayor miseria. Esta decisión indignó a Romero de Torres, que se quejaba de que este dato no se hubiera incluido en la necrología ${ }^{28}$.

Una vez recibida la carta, contestaba Antonio Garrido el 6 de febrero de $1917^{29}$. Tras leer la información y la necrología, se lamentaba profundamente de las circunstancias del fallecimiento, pues si la pérdida de un artista siempre era sensible, más aún la de González y Giménez. Le resultaba dolorosa por la "triste y precaria situación de una familia obligada a recurrir a la caridad pública" para sufragar los gastos del entierro. Más aún de un hombre que había dedicado su existencia a la difusión y enseñanza de las Bellas Artes, y que había recibido en vida varias distinciones y premios.

Finalmente, se alude al motivo de las pesquisas realizadas en torno al artista. Desde Madrid, Garrido estaba organizando las Comisiones de Monumentos y el personal de ambas Academias que formaba parte de las mismas. Por ello, probablemente se toparía con el nombre del artista, y querría tener todos los datos disponibles.

Cuando se editó el Anuario de la Academia de San Fernando correspondiente al año 1917 ya no figuraba entre los correspondientes González y Giménez, pues murió a comienzos de ese año y, tras las pesquisas sobre su figura, en la Academia de San Fernando estaría muy reciente su memoria ${ }^{30}$. El problema relativo a la pérdida de información sobre González y Giménez vino ligado a la falta de actualización de los datos del Anuario. De hecho, en el volumen correspondiente al año 1916 aún figuraba en Sevilla, cuando hacía años que se había trasladado a Córdoba y que se había jubilado ${ }^{31}$. Parece ser que en ese mismo año se tuvo noticia del traslado a Córdoba, pues de lo contrario habría aparecido recogida su nueva ciudad de residencia en el volumen de 1916. Como ya estaba jubilado y muy probablemente sus últimos años en activo los pasase dedicados a la docencia -ya que los diversos proyectos de monumentos públicos que presentó a lo largo de su vida no llegaron a realizarse-, el recuerdo de su actividad como escultor quedaba muy lejano. Curiosamente, Antonio Garrido tuvo relación con dos ciudades en las que

${ }^{28}$ Aunque Romero de Torres siguió en el cargo como director del Museo, unos pocos días antes del fallecimiento de González y Giménez firmaba el ministro de Instrucción Pública una Real Orden disponiendo que cesase en su cargo al frente del Museo. Véase $L a$ Correspondencia de España, año LXVIII, n ${ }^{\circ} 21.517,10-1-1917$, p. 5. No obstante, el pintor continuó al frente de la institución, como se aprecia en el voto de gracias que el Patronato del Museo Provincial de Bellas Artes le concedió en octubre de ese año por las reformas que había hecho en el Museo. Véase El defensor de Córdoba, año XIX, nº 5.538 , 24-10-1917, p. 2.

29 ARABASF, Comisión provincial de Monumentos históricos y artísticos de Córdoba, exp. 4-58-12, Carta de Antonio Garrido a Enrique Romero de Torres, 6-2-1917. La fecha está escrita debajo de otra tachada, correspondiente al 31 de enero de 1917.

${ }^{30}$ Real Academia de Bellas Artes de San Fernando. Año de 1917. Madrid, 1917.

31 Real Academia de Bellas Artes de San Fernando. Año de 1916. Madrid, 1916, p. 157. 
residió y trabajó González y Giménez. Garrido era natural de La Coruña, y después había pasado por Valladolid, estudiando en la Escuela Militar ${ }^{32}$. Probablemente, el hecho de que Garrido procediese de otro ámbito -era militar y escritor-, unido a que los periodos de estancia de ambos en las ciudades mencionadas fueran distintos, hizo que no tuviese conocimiento. Garrido no pasó por las Escuelas de Bellas Artes de La Coruña, y en Valladolid estuvo varios años antes que el escultor.

Más extrañas parecen las circunstancias del desconocimiento de González y Giménez por parte de Enrique Romero de Torres. Este último artista había nacido en Córdoba en 1876, pero se trasladó a Madrid. A Córdoba volvió a la muerte de su padre, Rafael Romero Barros, para dirigir el Museo Provincial y ocupar la cátedra de Bellas Artes ${ }^{33}$. En 1931 crearía el Museo Julio Romero de Torres $^{34}$. Parece lógico que tuviera conocimiento de la labor de González y Giménez, más aún cuando otro pintor que ejerció la docencia en Córdoba, Eduardo Vassallo, había asistido al enlace matrimonial de la hija de González y Giménez, de quien era compañero en la institución docente. Romero de Torres, docente también en Córdoba ${ }^{35}$, tendría que conocer al menos a Vassallo, y podría haberle preguntado a él, quien le hubiera podido dar cumplida información del escultor granadino.

Falta por analizar el papel de Mateo Inurria en la jubilación y ostracismo de González y Giménez. El escultor cordobés, más joven que González y Giménez - puesto que había nacido en 1867, justo cuando este ganaba una segunda medalla en la Exposición Nacional por su grupo en yeso Los últimos momentos de Numancia-, fue nombrado director de la Escuela Municipal de Artes y Oficios de Córdoba en $1901^{36}$. Precisamente, a fines de septiembre de ese año era designado para que, como comisario regio, se entendiese con el Ayuntamiento en la creación

32 Discursos leídos ante la Real Academia de Bellas Artes de San Fernando en la recepción pública del señor D. Antonio Garrido y Villazán..., op. cit., pp. 33-34. La información se aporta en la contestación al discurso, a cargo de Enrique Serrano Fatigati.

$33 \mathrm{https} / /$ www.museodelprado.es/aprende/enciclopedia/voz/romero-de-torresenrique/7b717691-31db-4d12-846f-ccafb6f97e96 (Consultado el 29-9-2017).

${ }^{34}$ Diccionario de pintores y escultores españoles del siglo XX. Vol. 12. Madrid, 1994, p. 3700 .

35 Ibidem.

${ }^{36}$ El defensor de Córdoba, año III, n ${ }^{\circ}$ 579, 16-8-1901, p. 1. Ese día aparecía dando el visto bueno a la publicación del periodo de matrículas para el curso 1901-1902. Inurria, hijo de escultor, había estudiado en Córdoba y luego en Madrid, y en su obra demuestra la influencia que todavía a inicios del siglo XX ejercía el realismo decimonónico, pasando en la segunda década del siglo hacia el clasicismo. Véase PRECKLER, Ana María: Historia del arte universal de los siglos XIX y XX. Vol. 2. Madrid, 2003, pp. 553-554. Sería en Madrid donde cosechase sus mayores éxitos y reconocimientos oficiales, y en la capital fallecería en febrero de 1924. Véase MONTES RUIZ, Ramón: "Los dibujos de Inurria. Trazos de 
de la Escuela Superior de Artes e Industrias ${ }^{37}$. En 1909, momento en que ya se encontraba en la ciudad González y Giménez, Inurria figuraba como director de la Escuela de Artes Industriales ${ }^{38}$. González y Giménez fue profesor durante ese tiempo. Pero ya en octubre de 1911 Inurria era nombrado profesor de término de modelado y vaciado de la Escuela de Artes y Oficios de Madrid ${ }^{39}$. Y es entonces, en 1911, cuando se jubiló González y Giménez, a la edad de 73 años, según indica Pardo Canalís. Este autor incluía una carta fechada el 28 de noviembre de 1911 y publicada en el Boletín Oficial del Ministerio de Instrucción Pública y Bellas Artes el 12 de diciembre de ese año, en la que se resolvía un expediente promovido por González y Giménez. Se indicaba que el profesor pretendía continuar en el desempeño de su cargo a los 73 años. Pero los informes emitidos por los médicos y por las autoridades académicas indicaban que no estaba "apto física ni intelectualmente para seguir desempeñando su cátedra" ${ }^{40}$. Por ello, se le negaba al artista la continuación en el servicio activo de la enseñanza, declarándolo "jubilado con el haber que por clasificación le corresponda". Al final aparecían mencionados el rector de la Universidad de Sevilla y el director de la Escuela de Artes y Oficios de Córdoba. Teniendo en cuenta que a comienzos de noviembre de 1911 se había dado el visto bueno a la continuación en activo de González y Giménez, y que a finales de ese mes los informes eran negativos, algo hubo de pasar. No sabemos si realmente el estado de salud del escultor se vio deteriorado en el plazo de unos quince días, o si bien, tal como se indica en el Boletín del Ministerio, junto a informes médicos, pesó el criterio de las autoridades académicas -entre las que se encontraría Inurria, nombrado profesor en Madrid en octubre--. Como quiera que sucediera, el caso es que la pensión que le pudo quedar debió de ser a todas luces insuficiente para mantenerse en condiciones dignas, pues así lo lamentaba Romero de Torres en carta dirigida a Garrido, a la que nos hemos referido antes. Da la sensación de que Inurria realizó un movimiento al final de su periodo en Córdoba, para evitar que González y Giménez siguiese desempeñando su labor docente tras su marcha a Madrid. De hecho, quien le sucedió al frente de la institución cordobesa fue Eduardo Vassallo, que tenía relación con el anciano profesor granadino y quien quizás hubiera optado por apoyar la prolongación de su

su pensamiento", en Mateo Inurria. Cuadernos de viaje. Córdoba, 1994, s. p.; y Diccionario de pintores y escultores españoles del siglo XX. Vol. 7. Madrid, 1994, p. 2079.

37 Diario de Córdoba, año LII, n $15.284,8-10-1901$, p. 2.

${ }_{38}$ Almanaque del obispado de Córdoba para el Año de 1909. Córdoba, 1908, p. 35.

${ }^{39}$ La Correspondencia de España, año LXII, no 19.612, 23-10-1911, p. 6. Con motivo del ascenso y traslado de Inurria a Madrid se celebró un banquete con gran número de comensales. Véase La Correspondencia de España, año LXII, n 19.622, 2-11-1911, p. 7.

${ }^{40}$ PARDO CANALÍS, Enrique: "Informe de Federico de Madrazo...”, op. cit., p. 231. 
vida docente, ya que así se había aprobado poco antes ${ }^{41}$. Precisamente, Vassallo había desempeñado el cargo de secretario de la Escuela mientras González y Giménez era director, ambos con carácter accidental ${ }^{42}$, por lo que la relación entre ambos hubo de ser cercana. Ahora bien, un mal estado de salud contribuiría a explicar por qué el artista jubilado desapareció de la esfera pública y no se relacionó con nadie en sus últimos años, lo que debió de contribuir a su ostracismo. A ello se sumaría el pesar por haber sido obligado a jubilarse estando en condiciones de seguir su labor docente.

\section{CONCLUSIÓN}

Los últimos años de vida del escultor y profesor granadino José González y Giménez fueron duros para el artista. Después de toda una vida dedicada a la escultura, que le reportó varios premios importantes en España y en Italia, y también de su desempeño como profesor en diversas escuelas de artes y oficios y academias nacionales y extranjeras, moriría en la pobreza. En un caso de injusto olvido, la memoria de su actividad se perdió al final de su vida, y fue por el interés de Antonio Garrido Villazán como, desde la Academia de Bellas Artes de San Fernando, se pudo recabar información sobre quien era académico correspondiente de la institución desde hacía años. Sería en la necrológica aparecida en el Diario de Córdoba donde se recordase al artista fallecido hace ahora un siglo. Viudo, pobre y con dos hijos a su cargo -ya que el marido de Aurelia había fallecido en 1916-, pasó esa etapa retirado del mundo artístico y olvidado por sus compañeros en la Escuela de Artes y Oficios. Quizás la situación de desconocimiento entre la sociedad cordobesa estribase en que solo trabajó en la ciudad durante tres años, siendo ya muy mayor, y sin participar activamente en la vida social de la ciudad. Una vez jubilado, pocos eran los amigos que le quedaron en Córdoba, ciudad en la que no tendría más arraigo. El varapalo de su jubilación debió de apartarlo definitivamente de la vida pública, quedando recluido en su casa como lamentaba Romero de Torres.

Fecha de recepción: 30 de octubre de 2017

Fecha de aceptación: 12 de abril de 2018

${ }^{41}$ Vassallo cesó en el cargo de director de la Escuela de Artes y Oficios en enero de 1914, siendo nombrado como sucesor Ricardo Agrasot. Véase La Correspondencia de España, año LXV, no $20.417,5-1-1914$, p. 7. No obstante, Vassallo seguía en Córdoba a fines de 1914, cuando lo encontramos como profesor de la clase de dibujo lineal de la Escuela de Artes y Oficios. Véase Diario de Córdoba, año LXV, nº 19.840, 12-11-1914, p. 1.

${ }^{42}$ Como Director A. y Secretario A. - accidental-aparecen mencionados en el Diario de Córdoba, año LXI, no 18.438, 18-8-1910, p. 1. 